\title{
Clinical Reasoning: A 42-year-old woman with progressive cognitive difficulties and gait imbalance
}

Michaël C.C. Slama, MD, PhD, Matthew Torre, MD, Stephanie M. Shatzman, MD, Joome Suh, MD, Joel B. Krier, MD, Umberto De Girolami, MD, Dorlan J. Kimbrough, MD, and Tracey A. Milligan, MD

Neurology ${ }^{\circledR}$ 2020;94:e1219-e1226. doi:10.1212/WNL.0000000000009099

\section{Correspondence}

Dr. Slama

mslama@partners.org

\section{Section 1}

A 42-year-old woman presented with 6 months of generalized fatigue, disequilibrium, subjective leg weakness, and difficulty concentrating and completing complex tasks. She had a history of psoriatic arthritis, previously treated with the tumor necrosis factor- $\alpha$ (TNF- $\alpha$ ) inhibitor etanercept, which was discontinued about 2 months prior to onset of neurologic symptoms. There was no family history of a similar clinical syndrome. Initial neurologic examination was normal, including normal attention with serial $7 \mathrm{~s}$, normal immediate and delayed recall of 3 words, normal muscle tone, full strength with no pronator drift, normal and symmetric reflexes with negative Hoffman signs and flexor plantar responses, intact coordination to finger and foot tapping, unremarkable gait with intact ability to tandem, and negative Romberg sign.

\section{Questions for consideration:}

1. What is the differential diagnosis for the patient's presentation?

2. What initial diagnostic workup could be obtained?

\section{GO TO SECTION 2}




\section{Section 2}

New-onset cognitive complaints in a middle-aged adult have a broad differential diagnosis. Common etiologies include sleep disorders (e.g., obstructive sleep apnea), endocrine disorders (e.g., hypothyroidism), metabolic disorders (e.g., cobalamin deficiency, hyperammonemia, or uremia), and psychiatric conditions (e.g., major depressive disorder). Despite a normal neurologic examination, the patient's symptoms raise the concern for a multifocal process involving the brain and perhaps the spinal cord. The history of autoimmunity and prior immunomodulation treatment lowers the threshold to obtain neuroimaging.
Thyroid function tests, cortisol, basic metabolic panel, complete blood counts, and cobalamin level were normal. HIV test was negative. A brain MRI with contrast showed extensive T2/fluid-attenuated inversion recovery (FLAIR) hyperintense signal abnormalities in the periventricular white matter, corona radiata, and corpus callosum (figure 1, A-D).

\section{Question for consideration:}

1. What is the radiologic differential diagnosis of T2/FLAIR hyperintense lesions in the cerebral white matter?

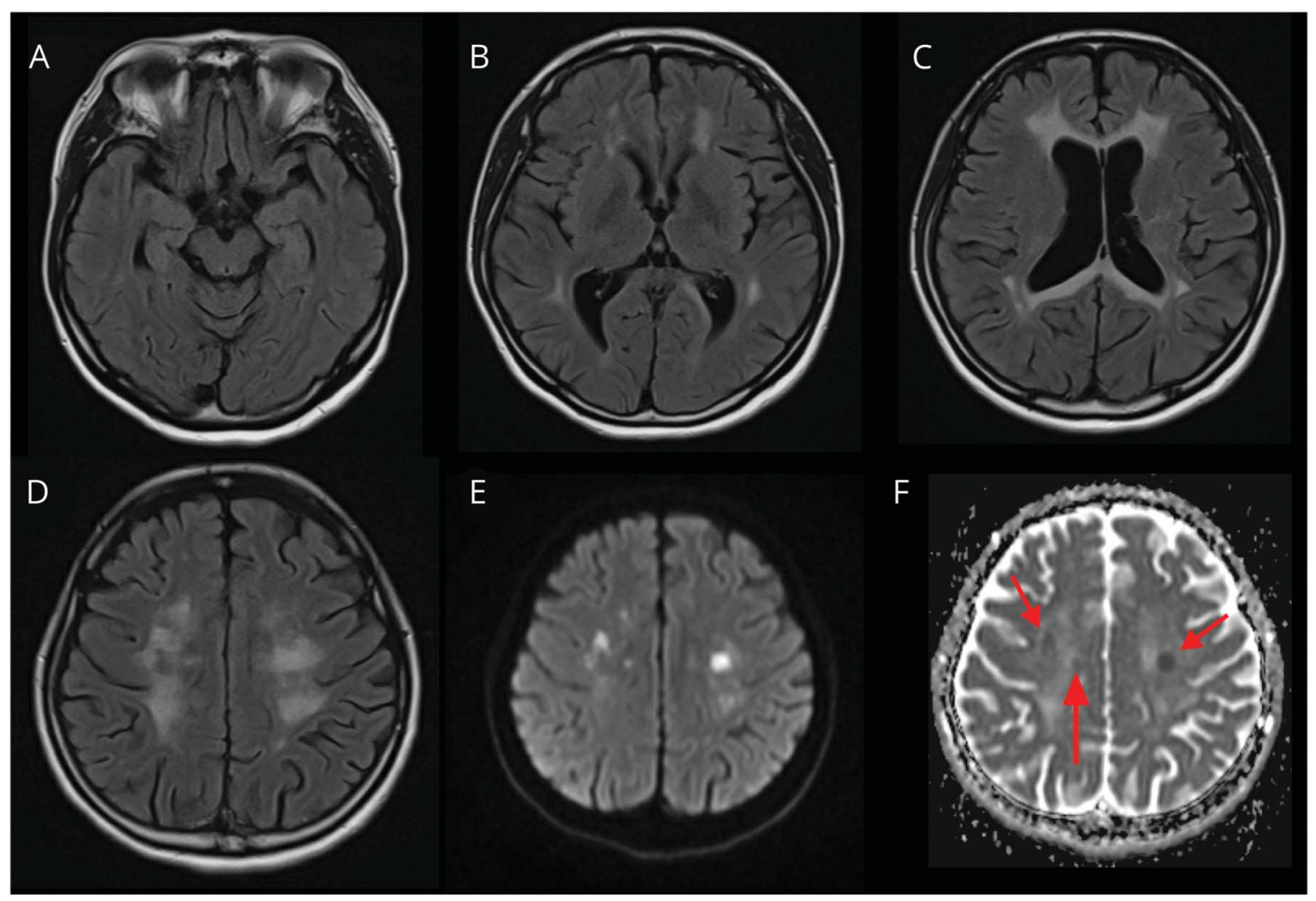

Initial brain MRI shows extensive T2/fluid-attenuated inversion recovery (FLAIR) hyperintense signal abnormalities in the cerebral white matter (A-D). On these axial sections, the signal abnormalities are fairly symmetrical, mostly periventricular, and coalesce at the genu and splenium of the corpus callosum. There were scattered areas of restricted diffusion, as can be seen in this representative axial section with areas of bright diffusion-weighted imaging signal (E) that were dark on apparent diffusion coefficient map ( $F$, arrows), within more diffuse signal abnormalities on T2/FLAIR (D). 


\section{Section 3}

The differential diagnosis of white matter lesions (WMLs) is broad (data available from GitHub, table e-1, github.com/ michaelslama/WMLs). The most common etiologies ${ }^{1}$ include demyelinating and immune-mediated conditions such as multiple sclerosis (MS), acute disseminated encephalomyelitis (ADEM), and neuromyelitis optica spectrum disorder (NMOSD); genetic conditions such as leukodystrophies and mitochondriopathies; infections such as HIV-associated dementia and progressive multifocal leukoencephalopathy (PML); inflammatory conditions such as Behçet disease and vasculitides; metabolic disorders such as cobalamin deficiency; neoplasms such as CNS lymphoma and gliomas; toxic exposures including drugs of abuse, chemotherapy, and radiation treatment; and vascular etiologies such as posterior reversible encephalopathy syndrome, small vessel ischemic disease, and migraines.

The distribution of WMLs can help narrow the differential. For instance, toxic, metabolic, and genetic conditions usually have a more diffuse and symmetric appearance, while acquired demyelinating conditions commonly start more focally and asymmetrically. The likelihood of MS can be inferred from the topography (typically periventricular, juxtacortical, infratentorial, and spinal) and shape (typically ovoid) of WMLs. Diffusion restriction and gadolinium contrast enhancement help further refine the radiologic differential.

In this case, the WMLs are fairly symmetric and confluent (figure 1, A-D). There are no clear ovoid or juxtacortical lesions suggesting MS. There is no contrast enhancement on T1 sequences (not shown), arguing against a high-grade glioma, CNS lymphoma, or an active inflammatory disorder. A few discrete areas restrict diffusion (figure 1, E and F), as can be seen in atherosclerotic microvascular disease (unlikely here without cardiovascular risk factors) and vasculitis. Cerebral autosomal dominant arteriopathy with subcortical infarcts and leukoencephalopathy (CADASIL) can also cause WMLs with discrete areas of diffusion restriction; however, sparing of the anterior temporal lobes (figure 1A), and absence of stroke/TIAs or migraines on history, make CADASIL unlikely. ${ }^{1,2}$

The patient's symptoms progressed over the following 3 months, with worsening gait difficulties, dysarthria, and incontinence of bowel and bladder. MRI of the cervical and thoracic spine was unremarkable. A 3-day course of 1,000 mg daily IV methylprednisolone was administered out of concern for demyelinating disease, perhaps related to prior treatment with etanercept. Steroids did not help her symptoms. Followup neurologic examination was notable for mild weakness in left lower extremity hip flexion, knee flexion, and ankle dorsiflexion. Reflexes were brisker on the left side, with a positive left Hoffman sign. Gait was now spastic.

\section{Questions for consideration:}

1. How does the clinical progression change the differential diagnosis?

2. What additional workup could be obtained?

\section{GO TO SECTION 4}




\section{Section 4}

The patient's symptoms progressed over a 3-month period. The examination findings point to an upper motor neuron process, consistent with progression of motor WMLs or new spinal cord lesions. Progression without exposure to etanercept in months and despite empiric IV steroids argues against demyelination from TNF- $\alpha$ inhibitor treatment. The subacute course is overall too slow for NMOSD or ADEM, and is more consistent with a neoplastic process, some types of infections (e.g., PML, neurosyphilis), and some inherited disorders presenting in adulthood (e.g., adult-onset leukodystrophies).

Repeat brain MRI only showed subtle radiologic progression (figure 2, B and C), with involvement of the corpus callosum over the full anterior-posterior axis (figure 2A). Repeat MRI of the cervical and thoracic spine was again unremarkable.

CSF showed normal glucose and total protein, $0-1$ leukocytes, no oligoclonal bands, normal immunoglobulin $\mathrm{G}$ index, and negative autoimmune encephalitis panel, JC virus PCR, cytology, and flow cytometry. Bloodwork included negative treponemal antibody, autoimmune encephalitis panel, and JC virus PCR. Erythrocyte sedimentation rate was elevated to $59 \mathrm{~mm} /$ $\mathrm{h}$, and C-reactive protein was elevated to $19.7 \mathrm{mg} / \mathrm{L}$, in the context of a psoriasis flare. A rheumatologic panel was notable for trace antinuclear antibodies, elevated rheumatoid factor, positive anti-CCP, and negative antineutrophil cytoplasmic antibodies, anti-dsDNA, anti-SSA/SSB, anti-Sm, anti-RNP, and antiphospholipid antibodies. $\mathrm{C} 3$ and $\mathrm{C} 4$ complement levels were normal. There was no cryoglobulinemia. Metabolic studies including lactate, pyruvate, amino acid profile, fatty acid profile, urine organic acids, and peroxisomal analysis were nondiagnostic. A CT angiogram of the head did not show evidence of vasculopathy. A skin biopsy did not show signs of intravascular lymphoma. A PET scan of the brain did not show any foci of hypermetabolic activity. EEG monitoring did not show any seizures or signs of cortical irritability.

The patient underwent craniotomy and right frontal lobe biopsy. On pathologic evaluation, the white matter was markedly abnormal, with axonal spheroids seen on hematoxylin \& eosin (figure 2D) that were highlighted by Bielschowsky stain and SMI-31 immunostain (figure 2E). There was also patchy myelin loss, macrophages with phagocytosed myelin debris, reactive gliosis, and an admixed inflammatory cell infiltrate. The overall findings raised the possibility of adult-onset leukoencephalopathy with axonal spheroids and pigmented glia (ALSP). Additional stains are available from GitHub (figure e-1, github.com/michaelslama/WMLs).

\section{Questions for consideration:}

1. What additional testing could confirm the diagnosis of leukodystrophy?

2. What are the main types of adult-onset leukodystrophies and what are their clinical and radiologic characteristics?

Figure 2 Progression of white matter lesions on MRI and neuropathologic findings

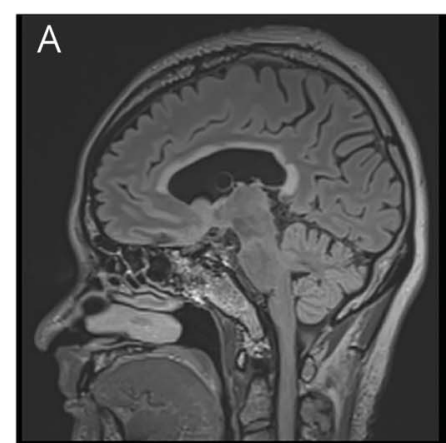

\section{B}

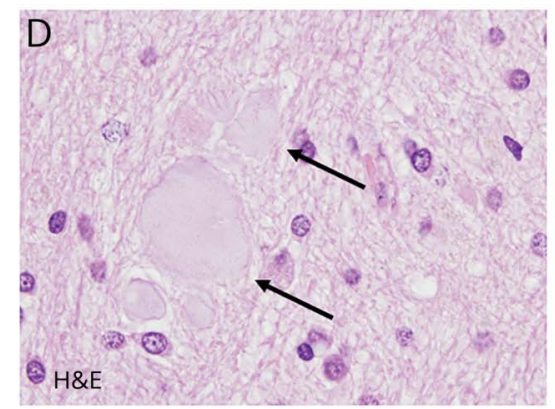

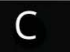
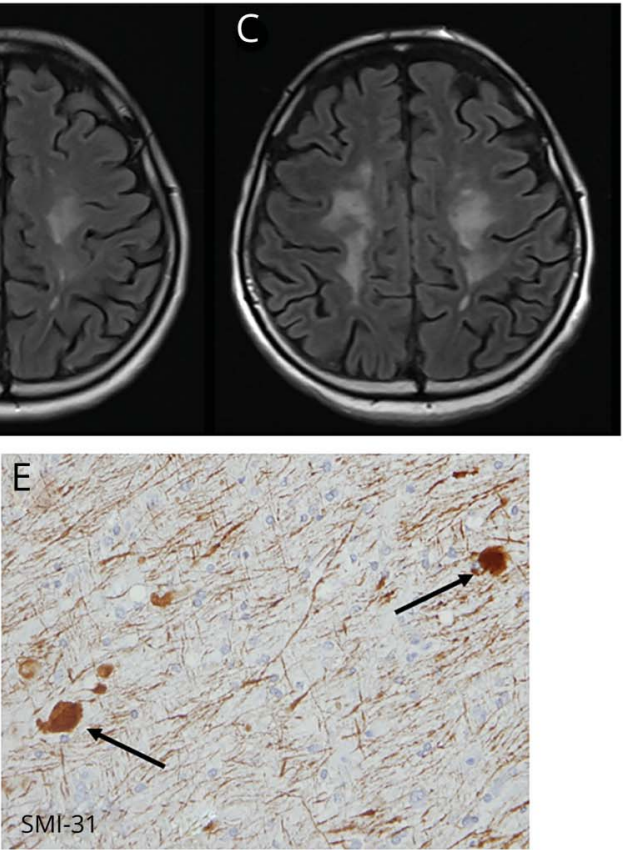

(A) Parasagittal T2/fluid-attenuated inversion recovery (FLAIR) cut of a brain MRI obtained about 3 months after initial MRI shows the extent of white matter disease involving the corpus callosum. (B, C) Axial T2/FLAIR cuts show subtle radiographic progression over time (B: initial MRI; C: MRI obtained about 4 months after B). (D) The patient's right frontal lobe biopsy shows markedly abnormal white matter containing axonal spheroids (arrows, hematoxylin \& eosin, $\times 1,000$ ) that were highlighted by SMI-31 immunostain $(E$, arrows, $\times 400)$. 


\section{Section 5}

Leukodystrophies (data available from GitHub, table e-2, github.com/michaelslama/WMLs) are a heterogeneous group of rare inherited conditions characterized by myelin destruction or myelination failure. Genetic testing can further confirm a pathologic diagnosis of leukodystrophy and identify the responsible mutation. A next-generation sequencing panel (GeneDX, Leukodystrophy Xpanded Panel) detected a missense mutation in the colony-stimulating factor 1 receptor $(C S F 1 R)$ gene. CSF1R encodes a tyrosine kinase receptor expressed on microglia (the resident macrophages of the brain) and involved in their proliferation and survival. ${ }^{3}$ Mutations in CSF1R are linked to ALSP. ${ }^{4}$ The patient's specific CSF1R gene variant (CSF1R p.R777Q) on exon 18 has been previously reported in ALSP. ${ }^{5}$

Leukodystrophies are difficult to diagnose on the basis of clinical presentation alone. In childhood, they usually present with subtle changes in personality and cognition, preceding loss of motor milestones, followed by progressive motor and coordination deficits. ${ }^{6}$ The most common childhood-onset leukodystrophies include X-linked adrenoleukodystrophy (X-ALD), globoid cell leukodystrophy (Krabbe disease), metachromatic leukodystrophy, Canavan disease, and Alexander disease. ${ }^{6,7}$

Figure 3 Algorithm for diagnosing the main types of leukodystrophies that can present in adulthood

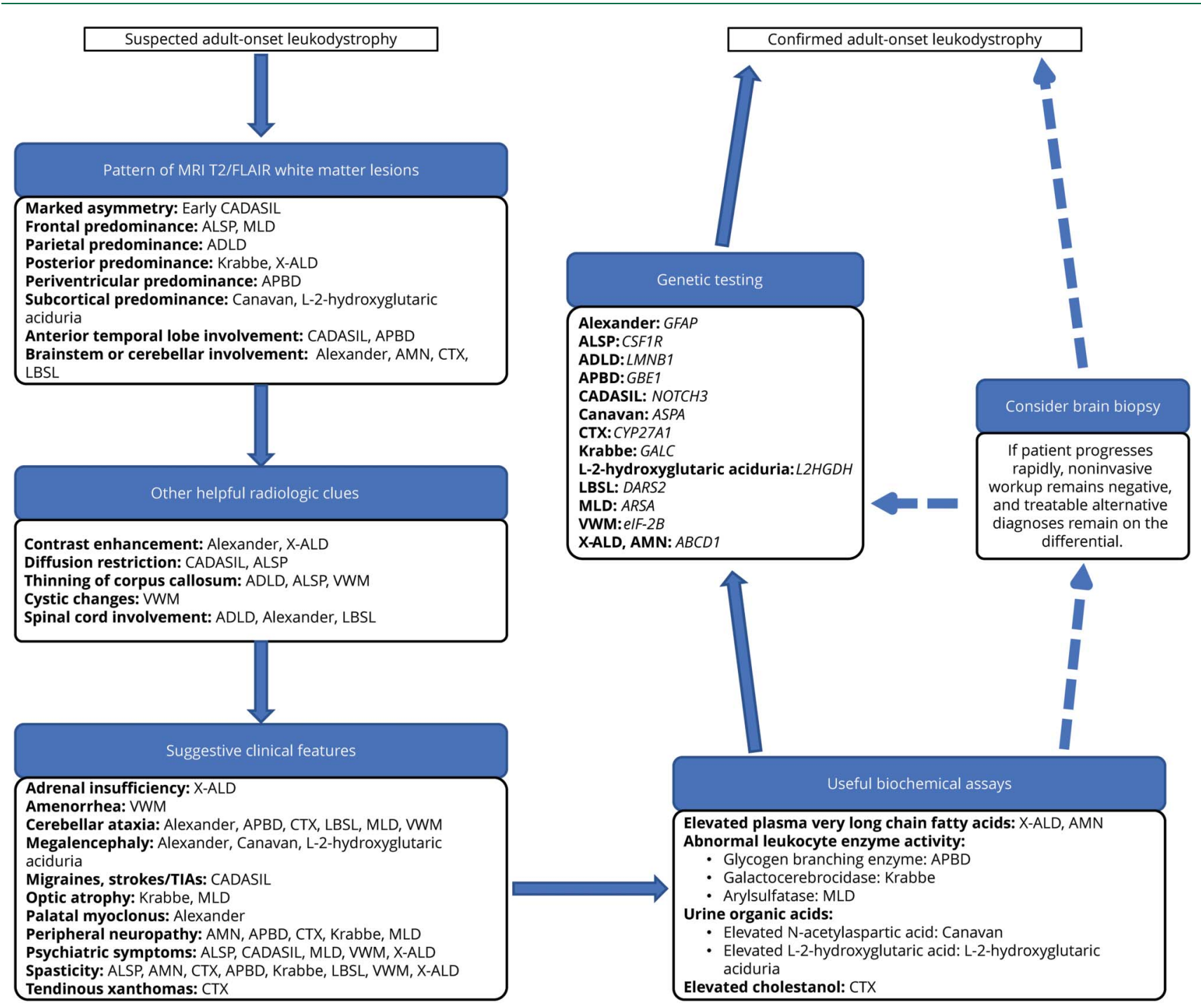

Once an adult-onset leukodystrophy is suspected, the differential diagnosis can be narrowed down based on MRI T2/fluid-attenuated inversion recovery (FLAIR) pattern of abnormalities, additional radiologic clues, and associated clinical features. ${ }^{6-8}$ Ascertaining the diagnosis requires specific biochemical assays and genetic testing (the most commonly affected genes are italicized). Brain biopsy may be indicated in some clinical contexts. ADLD = adult-onset autosomal dominant leukodystrophy; ALSP = adult-onset leukoencephalopathy with axonal spheroids and pigmented glia; $\mathrm{AMN}=$ adrenomyeloneuropathy; APBD = adult polyglucosan body disease; CADASIL = cerebral autosomal dominant arteriopathy with subcortical infarcts and leukoencephalopathy; CTX = cerebrotendinous xanthomatosis; LBSL = leukoencephalopathy with brainstem and spinal cord involvement and elevated lactate; MLD = metachromatic leukodystrophy; VWM = vanishing white matter disease; X-ALD = X-linked adrenoleukodystrophy. 
The leukodystrophies above can also present in adulthood. Other leukodystrophies primarily present in adulthood. These include ALSP, vanishing white matter (VWM) disease, and adult polyglucosan body disease. ${ }^{6,7}$ Adult-onset leukodystrophies often present with neuropsychiatric symptoms, followed by gait difficulties, lower limb spasticity, impaired coordination, and dysarthria. Specific clinical features (e.g., peripheral neuropathy, adrenal insufficiency) and imaging characteristics can help identify the type of leukodystrophy (figure 3). ${ }^{6-8}$
In ALSP, the WMLs are usually bilateral, but are not always symmetrical or confluent. The periventricular and subcortical white matter of the frontal lobes is commonly involved. ${ }^{3,9}$ Diffusion restriction on MRI is more characteristic of ALSP and CADASIL. ${ }^{10}$ Thinning of the corpus callosum is more common in ALSP and VWM. $3,7,9$

\section{Questions for consideration:}

1. What is the typical clinical course of ALSP?

2. How is ALSP treated?

GO TO SECTION 6 


\section{Section 6}

ALSP groups together 2 entities with overlapping neuropathologic features: hereditary diffuse leukoencephalopathy with spheroids and pigmentary orthochromatic leukodystrophy, both associated with CSF1R mutation. ${ }^{3,9}$ Inheritance is usually autosomal dominant, although sporadic cases have also been reported. ${ }^{3}$ ALSP usually presents between the ages of 30 and 50 , with prominent neuropsychiatric symptoms (including executive dysfunction, behavioral changes, depression, and psychosis), followed by gait dysfunction, limb weakness, ataxia, and in some cases asymmetric parkinsonism. ${ }^{3-5}$ Dysarthria and dysphagia are common later in the course. Seizures may develop in over $50 \%$ of cases. ${ }^{3}$ The disease progresses to a debilitating dementia and death within 7 years on average.,

Treatment is focused on managing complications including seizures, neuropsychiatric symptoms, spasticity, and dystonias. To date, no treatment is proven to stabilize or reverse the clinical progression. A single case of hematopoietic stem cell transplantation (HSCT) in ALSP is available in the literature. ${ }^{11}$ In this case report, the disease stabilized within 6 months of transplantation, in contrast to 3 affected siblings who did not receive HSCT. While there are no reported series of HSCT in ALSP, this suggests that HSCT may be beneficial and should be investigated further as a potential disease-modifying therapeutic approach.

\section{Discussion}

Progress in MRI technology has improved detection of WMLs. ${ }^{6}$ Yet recognizing an adult-onset leukodystrophy can be challenging, in part because of the nonspecific neuropsychiatric complaints often reported on presentation. Features that should raise suspicion include a subacute course and absent risk factors for more common causes of WMLs. Family history is an important clue, although de novo mutations can also arise. This was the case for our patient, whose parents both tested negative for the variant.

In our case, the marked progression of signs and symptoms over weeks to months did not correlate with only subtle radiologic progression of the WMLs. This clinicoradiologic disconnect has been previously reported in ALSP. ${ }^{9}$ Prominent WMLs and ventricular enlargement can be found in asymptomatic CSF1R mutation carriers. ${ }^{10}$

While the overall clinical progression and imaging findings are helpful to suggest a diagnosis of leukodystrophy, there are no known biochemical or clinical criteria to make a diagnosis of ALSP. In this case, an extensive laboratory and radiologic workup failed to yield a diagnosis, while neurologic deficits continued to worsen. Because treatable neoplastic, infectious, and inflammatory etiologies remained on the differential, a brain biopsy was obtained to clarify the diagnosis. Ultimately, the diagnosis was made based on neuropathologic features and genetic testing. Further research is needed to fully understand this rare condition and develop treatments to halt clinical progression. Similar to the successes seen in other leukodystrophies such as X-ALD, stem cell transplantation and gene therapy may be a promising avenue.

\section{Acknowledgment}

The authors thank Drs. Florian Eichler, Alissa Mueller, and Angela O'Neal for their input on this case.

\section{Study funding}

No targeted funding reported.

\section{Disclosure}

The authors report no disclosures relevant to the manuscript. Go to Neurology.org/N for full disclosures.

\begin{tabular}{|c|c|c|}
\hline Name & Location & Contribution \\
\hline $\begin{array}{l}\text { Michaël C.C. } \\
\text { Slama, MD, } \\
\text { PhD }\end{array}$ & $\begin{array}{l}\text { Harvard } \\
\text { Medical School, } \\
\text { Boston }\end{array}$ & $\begin{array}{l}\text { Interpreted the data, drafted the } \\
\text { manuscript for intellectual content }\end{array}$ \\
\hline $\begin{array}{l}\text { Matthew } \\
\text { Torre, MD }\end{array}$ & $\begin{array}{l}\text { Harvard } \\
\text { Medical School, } \\
\text { Boston }\end{array}$ & $\begin{array}{l}\text { Major role in the acquisition of data, } \\
\text { interpreted the data, drafted the } \\
\text { manuscript for intellectual content }\end{array}$ \\
\hline $\begin{array}{l}\text { Stephanie M. } \\
\text { Shatzman, MD }\end{array}$ & $\begin{array}{l}\text { Harvard } \\
\text { Medical School, } \\
\text { Boston }\end{array}$ & $\begin{array}{l}\text { Major role in the acquisition of data, } \\
\text { interpreted the data }\end{array}$ \\
\hline $\begin{array}{l}\text { Joome Suh, } \\
\text { MD }\end{array}$ & $\begin{array}{l}\text { Harvard } \\
\text { Medical School, } \\
\text { Boston }\end{array}$ & $\begin{array}{l}\text { Major role in the acquisition of data, } \\
\text { interpreted the data }\end{array}$ \\
\hline $\begin{array}{l}\text { Joel B. Krier, } \\
\text { MD }\end{array}$ & $\begin{array}{l}\text { Harvard } \\
\text { Medical School, } \\
\text { Boston }\end{array}$ & $\begin{array}{l}\text { Major role in the acquisition of data, } \\
\text { interpreted the data }\end{array}$ \\
\hline $\begin{array}{l}\text { Umberto De } \\
\text { Girolami, MD }\end{array}$ & $\begin{array}{l}\text { Harvard } \\
\text { Medical School, } \\
\text { Boston }\end{array}$ & $\begin{array}{l}\text { Major role in the acquisition of data, } \\
\text { interpreted the data }\end{array}$ \\
\hline $\begin{array}{l}\text { Dorlan J. } \\
\text { Kimbrough, } \\
\text { MD }\end{array}$ & $\begin{array}{l}\text { Harvard } \\
\text { Medical School, } \\
\text { Boston }\end{array}$ & $\begin{array}{l}\text { Major role in the acquisition of data, } \\
\text { interpreted the data, revised the } \\
\text { manuscript for intellectual content }\end{array}$ \\
\hline $\begin{array}{l}\text { Tracey A. } \\
\text { Milligan, MD }\end{array}$ & $\begin{array}{l}\text { Harvard } \\
\text { Medical School, } \\
\text { Boston }\end{array}$ & $\begin{array}{l}\text { Major role in the acquisition of } \\
\text { data, interpreted the data, } \\
\text { revised the manuscript for } \\
\text { intellectual content }\end{array}$ \\
\hline
\end{tabular}

\section{References}

1. Schmahmann JD, Smith EE, Eichler FS, Filley CM. Cerebral white matter: neuroanatomy, clinical neurology, and neurobehavioral correlates. Ann NY Acad Sci 2008; 1142:266-309.

2. Dichgans M, Mayer M, Uttner I, et al. The phenotypic spectrum of CADASIL: clinical findings in 102 cases. Ann Neurol 1998;44:731-739.

3. Adams SJ, Kirk A, Auer RN. Adult-onset leukoencephalopathy with axonal spheroids and pigmented glia (ALSP): integrating the literature on hereditary diffuse leukoencephalopathy with spheroids (HDLS) and pigmentary orthochromatic leukodystrophy (POLD). J Clin Neurosci 2018;48:42-49.

4. Rademakers R, Baker M, Nicholson AM, et al. Mutations in the colony stimulating factor 1 receptor (CSF1R) gene cause hereditary diffuse leukoencephalopathy with spheroids. Nat Genet 2011;44:200-205.

5. Konno T, Yoshida K, Mizuno T, et al. Clinical and genetic characterization of adultonset leukoencephalopathy with axonal spheroids and pigmented glia associated with CSF1R mutation. Eur J Neurol 2017;24:37-45.

6. Costello DJ, Eichler AF, Eichler FS. Leukodystrophies: classification, diagnosis, and treatment. Neurologist 2009;15:319-328. 
7. Ahmed RM, Murphy E, Davagnanam I, et al. A practical approach to diagnosing adult onset leukodystrophies. J Neurol Neurosurg Psychiatry 2014;85:770-781.

8. Resende LL, de Paiva ARB, Kok F, da Costa Leite C, Lucato LT. Adult leukodystrophies: a step-by-step diagnostic approach. Radiographics 2019;39:153-168.

9. Konno T, Tada M, Tada M, et al. Haploinsufficiency of CSF-1R and clinicopathologic characterization in patients with HDLS. Neurology 2014;82:139-148.
10. Bender B, Klose U, Lindig T, et al. Imaging features in conventional MRI, spectroscopy and diffusion weighted images of hereditary diffuse leukoencephalopathy with axonal spheroids (HDLS). J Neurol 2014;261: 2351-2359.

11. Eichler FS, Li J, Guo Y, et al. CSF1R mosaicism in a family with hereditary diffuse leukoencephalopathy with spheroids. Brain 2016;139:1666-1672. 


\section{Neurology}

\section{Clinical Reasoning: A 42-year-old woman with progressive cognitive difficulties and gait imbalance}

Michaël C.C. Slama, Matthew Torre, Stephanie M. Shatzman, et al.

Neurology 2020;94;e1219-e1226 Published Online before print February 27, 2020

DOI 10.1212/WNL.0000000000009099

This information is current as of February 27, 2020

\section{Updated Information \&} Services

References

Subspecialty Collections

Permissions \& Licensing

Reprints including high resolution figures, can be found at: http://n.neurology.org/content/94/11/e1219.full

This article cites 11 articles, 2 of which you can access for free at: http://n.neurology.org/content/94/11/e1219.full\#ref-list-1

This article, along with others on similar topics, appears in the following collection(s):

All Cognitive Disorders/Dementia

http://n.neurology.org/cgi/collection/all_cognitive_disorders_dementia All Demyelinating disease (CNS)

http://n.neurology.org/cgi/collection/all_demyelinating_disease_cns

All Genetics

http://n.neurology.org/cgi/collection/all_genetics

Leukodystrophies

http://n.neurology.org/cgi/collection/leukodystrophies

MRI

http://n.neurology.org/cgi/collection/mri

Information about reproducing this article in parts (figures,tables) or in its entirety can be found online at:

http://www.neurology.org/about/about_the_journal\#permissions

Information about ordering reprints can be found online:

http://n.neurology.org/subscribers/advertise

Neurology ${ }^{\circledR}$ is the official journal of the American Academy of Neurology. Published continuously since 1951, it is now a weekly with 48 issues per year. Copyright () 2020 American Academy of Neurology. All rights reserved. Print ISSN: 0028-3878. Online ISSN: 1526-632X.

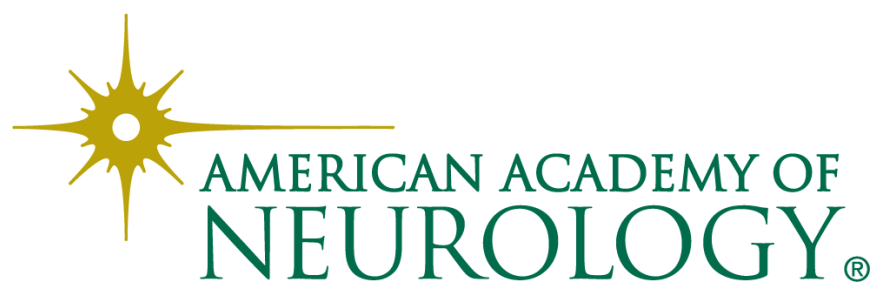

